\title{
BEBERAPA ASPEK BIOLOGI CAKALANG (Katsuwonus pelamis) YANG DIDARATKAN DI BITUNG, SULAWESI UTARA
}

\author{
Budi Nugraha ${ }^{1)}$ dan Siti Mardlijah' \\ 1) Peneliti pada Balai Riset Perikanan Laut, Muara Baru-Jakarta \\ Teregristrasi I tanggal: 11 Juli 2007; Diterima setelah perbaikan tanggal: 9 Oktober 2007; \\ Disetujui terbit tanggal: 19 Desember 2007
}

\begin{abstract}
ABSTRAK
Penelitian biologi ikan cakalang hasil tangkapan kapal huhate (pole and line) yang didaratkan di Bitung dilakukan di tempat pendaratan ikan, perusahaan perikanan, dan tempat pengasapan atau fufu cakalang. Aspek yang diteliti meliputi hubungan panjang bobot, rasio kelamin, tingkat kematangan gonad, dan fekunditas. Pengambilan contoh dilakukan pada bulan Juli dan September 2005. Dari hasil analisis hubungan panjang bobot diketahui bahwa pola pertumbuhan ikan cakalang bersifat allometrik positif. Perbandingan jenis kelamin betina dan jantan pada bulan Juli 1:0,73, sedangkan pada bulan September perbandingan 1:2,05. Tingkat kematangan gonad ikan jantan maupun betina didominasi oleh stadium III. Fekunditas telur berkisar antara 1.000.000 sampai dengan 14.000.000 butir.
\end{abstract}

KATAKUNCI: cakalang, kapal huhate, biologi, Bitung

\section{PENDAHULUAN}

Cakalang (Katsuwonus pelamis) merupakan kelompok ikan yang termasuk Scombroids kosmopolitan di perairan tropik dan sub tropik. Tuna, cakalang, dan tongkol merupakan komoditas utama di Indonesia setelah udang dengan nilai US \$ 182.200.000 atau $10,85 \%$ dari total ekspor perikanan tahun 1994 (Direktorat Jenderal Perikanan, 1996). Cakalang merupakan hasil tangkapan dominan di perairan Pasifik, komoditas ini menyumbangkan $66 \%$ dari total tangkapan perairan ini (Hampton et al., 1999). Peningkatan hasil tangkapan per unit upaya (catch per unit of effort) berlangsung terus sejak tahun 1990 sampai dengan 1995. Eksploitasi cakalang di Laut Pasifik sudah mendekati padat tangkap. Secara ekologi, ikan ini memiliki karakteristik tinggi dalam fekunditas, relatif cepat tumbuh serta laju kematian alamiah yang tinggi dalam waktu pendek (ICCAT, 1998).

Cakalang banyak ditemukan di semua perairan di dunia, tetapi jarang ditemukan di Laut Utara dan tidak pernah tertangkap di Laut Hitam. Ikan ini hidup di perairan dengan suhu di atas $15^{\circ} \mathrm{C}$ (Muss \& Nielsen, 1999). Cakalang merupakan ikan epipelagis yang tersebar di perairan dengan suhu antara 14,7 sampai dengan $30^{\circ} \mathrm{C}$. Larva hidup pada suhu di bawah $25^{\circ} \mathrm{C}$ (Collete \& Nauen, 2000). Ikan ini berasosiasi dengan daerah upwelling atau daerah dingin, perairan yang kaya nutrien yang akan membawa nutrien dari dasar ke permukaan perairan, daerah pertemuan antara massa air panas dan dingin. Daerah tersebut mempunyai produktivitas yang sangat tinggi. Menurut Collete \& Nauen (1983), cakalang jarang ditemukan pada kedalaman lebih dari $260 \mathrm{~m}$ dan bermigrasi secara berkelompok dan kadang-kadang berkelompok dengan ikan lain seperti tuna, paus, dan cucut. Ikan ini juga berkelompok dengan obyek yang mengapung di permukaan perairan (World Wide Fund for Nature, 1996). Gauldie \& Sharp (1996) mengatakan bahwa cakalang mempunyai pola migrasi yang bergerak dari utara ke selatan tetapi hal tersebut menjadi pertanyaan. Selanjutnya, Joseph et al. (1988) menemukan bahwa populasi cakalang di Pasifik mempunyai tingkat migrasi yang lebih tinggi dibandingkan dengan populasi yang ada di Atlantik meskipun perlu kajian yang lebih mendalam lagi.

Beberapa aspek biologi seperti panjang bobot, jenis kelamin, dan tingkat kematangan gonad merupakan pengetahuan dasar untuk mengetahui potensi produksi suatu stok ikan. Pengetahuan tentang jenis kelamin dan kematangan gonad dari ikan adalah salah satu pengetahuan dasar biologi reproduksi (Holden \& Raitt, 1974).

\section{KLASIFIKASI}

Cakalang (Katsuwonus pelamis) merupakan salah satu jenis ikan pelagis besar yang banyak tertangkap di perairan Indonesia khususnya di Laut Sulawesi. Mengacu pada Collette \& Nauen (1983), cakalang diklasifikasikan sebagai berikut:

Phylum : Chordata

Subphylum : Vertebrata

Superclass : Gnathostomata

Class :Teleostomi

Subclass : Actinopterygii

Order : Perciformes

Suborder : Scombroidei

Famili : Scombridae 


$$
\begin{array}{ll}
\text { Subfamili } & \text { : Scombrinae } \\
\text { Tribe } & : \text { Thunnini } \\
\text { Genus } & : \text { Katsuwonus } \\
\text { Spesies } & : \text { K. pelamis }
\end{array}
$$

\section{PERTUMBUHAN}

Analisis regresi terhadap ikan cakalang yang didaratkan di Bitung diperoleh persamaan hubungan panjang bobot $\mathrm{W}=0,0053 \mathrm{~L}^{3,3332}, \mathrm{r}=0,9486$ dengan nilai b (slope) $=3,3332$ (Gambar 1). Hasil pengujian nilai b terhadap nilai 3 pada taraf 95 dan $99 \%$ diperoleh nilai lebih besar dari $3(b>3)$ sehingga dapat dikatakan bahwa pertumbuhan cakalang bersifat allometrik positif di mana pertambahan bobot lebih besar daripada pertambahan panjang pangkat 3 (Bal \& Rao, 1984).

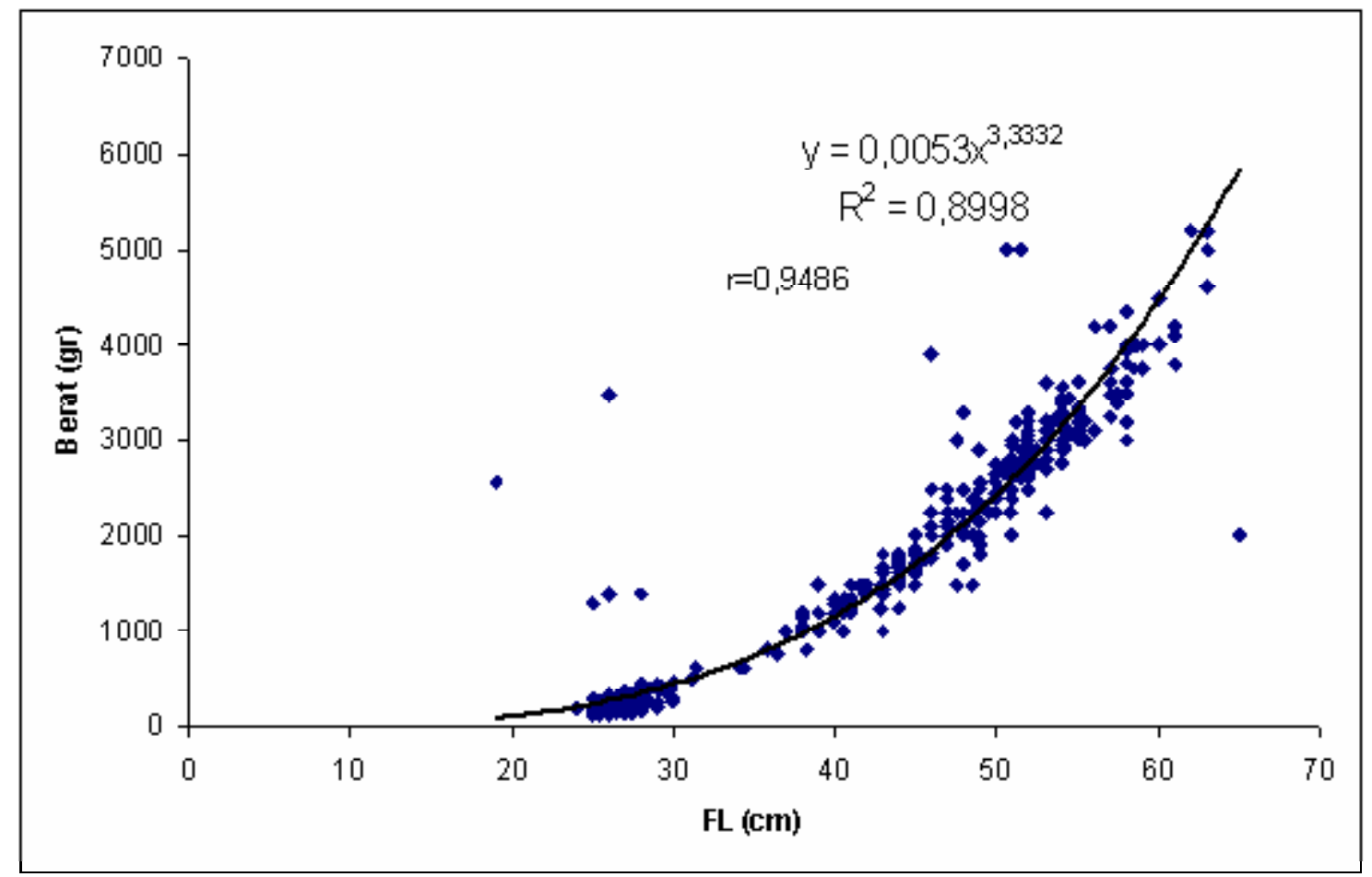

Gambar 1. Hubungan panjang bobot cakalang (Katsuwonus pelamis) yang didaratkan di Bitung.

Suhendrata \& Merta (1986) mengatakan bahwa pola pertumbuhan cakalang jantan dan betina di perairan Sorong bersifat allometrik positif di mana nilai b ikan jantan 3,26610 dan nilai b ikan betina 3,31319.
Sebagai pembanding lain dapat dilihat beberapa hasil penelitian di beberapa perairan yang disajikan pada Tabel 1 dan 2.

Tabel 1.

Hasil analisis regresi panjang bobot ikan cakalang di beberapa perairan

\begin{tabular}{lll}
\hline \multicolumn{1}{c}{ Perairan } & Nilai a & Nilai b \\
\hline Cuba & 0,0053 & 3,2200 \\
Somalia & 0,0086 & 3,2290 \\
Brazil & 0,0068 & 3,2800 \\
USA & 0,0022 & 3,3500 \\
Afrika Selatan & 0,0020 & 3,3780 \\
\hline
\end{tabular}

Sumber: http://www.fishbase.org

Tabel 2. Hasil analisis regresi panjang bobot ikan cakalang di beberapa perairan

\begin{tabular}{lcc}
\hline \multicolumn{1}{c}{ Perairan } & Nilai a & Nilai b \\
\hline New Zealand & $6,776 \times 10^{-5}$ & 3,29 \\
Hawai & $4,812 \times 10^{-6}$ & 3,368 \\
Pasifik Timur & $4,033 \times 10^{-6}$ & 3,413 \\
Atlantik Barat & $5,771 \times 10^{-6}$ & 3,353 \\
Atlantik Timur & $3,419 \times 10^{-6}$ & 3,456 \\
\hline
\end{tabular}

Sumber: Evans et al. (1978) 
Tabel tersebut menunjukkan bahwa hasil penelitian pada perairan yang berbeda menunjukkan semua nilai $b$ yang sama yaitu rata-rata lebih besar dari 3 ( $b>3$ ) atau menunjukkan bahwa pola pertumbuhan cakalang bersifat allometrik positif.

\section{RASIO KELAMIN}

Rasio kelamin memberi gambaran proporsi perbandingan individu jantan dan betina dari 1 populasi. Secara alamiah, perbandingannya adalah 1:1. Namun, di lapangan sering terjadi perbandingan rasio kelamin yang tidak seimbang. Hal ini, antara lain disebabkan oleh tingkah laku ikan menurut jenis kelamin, kondisi lingkungan, dan penangkapan ikan seperti yang dikatakan oleh Bal \& Rao (1984). Rasio kelamin ikan cakalang yang didaratkan di Bitung dikatakan pada Gambar 2.

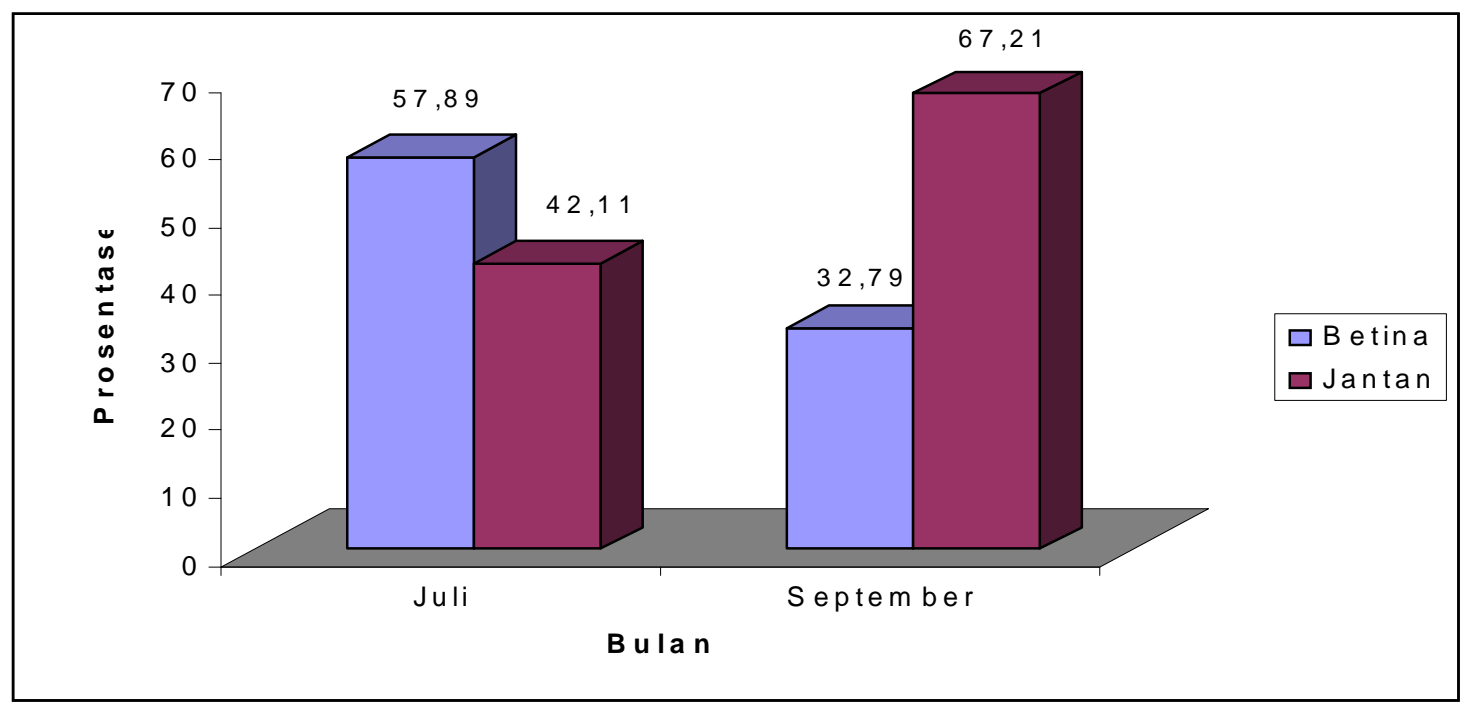

Gambar 2. Rasio kelamin cakalang yang didaratkan di Bitung pada bulan Juli dan September 2005.

Gambar tersebut menunjukkan rasio kelamin cakalang betina dan jantan pada bulan Juli 1:0,73, sedangkan pada bulan September perbandingan betina dan jantan 1:2,05. Perbedaan rasio kelamin betina dan jantan dalam suatu populasi berhubungan dengan pertumbuhan, kematian, dan penangkapan (Schaefer, 1998). Kemunculan jenis kelamin betina dalam kelas panjang dimungkinkan karena perbedaan angka pertumbuhan antara jenis kelamin, tetapi tidak ada bukti empiris untuk mendukung hipotesis tersebut. Proporsi betina lebih tinggi dalam kelas panjang yang lebih kecil juga berlaku untuk spesies cakalang, tetapi penentuan jenis kelamin tidak secara histologis sehingga hasil sedikit meragukan (Matsumoto et al., 1984). Hasil penelitian rasio kelamin cakalang di beberapa perairan disajikan pada Tabel 3 .

Tabel 3.

Rasio kelamin ikan cakalang di beberapa perairan

\begin{tabular}{lcl}
\hline \multicolumn{1}{c}{ Perairan } & $\begin{array}{c}\text { Rasio kelamin } \\
\text { Betina:Jantan }\end{array}$ & \multicolumn{1}{c}{ Referensi } \\
\hline $\begin{array}{l}\text { Samudera Atlantik } \\
\text { Carolina Utara }\end{array}$ & $1: 0,86$ & Batts (1972) \\
$\begin{array}{l}\text { Samudera Hindia } \\
\text { Madagaskar }\end{array}$ & $1: 0,83$ & Marcille \& Stequert (1976) \\
Samudera Pasifik & $1: 1,16$ & $\begin{array}{l}\text { Brock (1954) } \\
\text { Habib (1978) }\end{array}$ \\
Hawai & $1: 0,76$ & Schaefer \& Orange (1956) \\
New Zealand & $1: 0,73$ & Tester \& Nakamura (1957) \\
Pasifik Timur & $1: 1,57$ & Wade (1950) \\
Hawai & $1: 0,86$ & Waldron (1963) \\
Phillipina & $1: 1,09$ & \\
Jepang & & \\
\hline
\end{tabular}




\section{TINGKAT KEMATANGAN GONAD}

Analisis tingkat kematangan gonad memperlihatkan bahwa stadia III ikan betina mengalami penurunan dari bulan Juli sampai dengan September, demikian juga pada ikan jantan hal ini kemungkinan dikarenakan sebagian telur sudah berkembang menjadi stadia IV atau sebagian ikan bermigrasi ke tempat lain. Sementara itu, terjadi peningkatan persentase stadium II ikan jantan dari bulan Juli sampai dengan September. Sedangkan pada individu betina stadia kematangan gonad I dan II terjadi pada bulan September (Gambar 3).

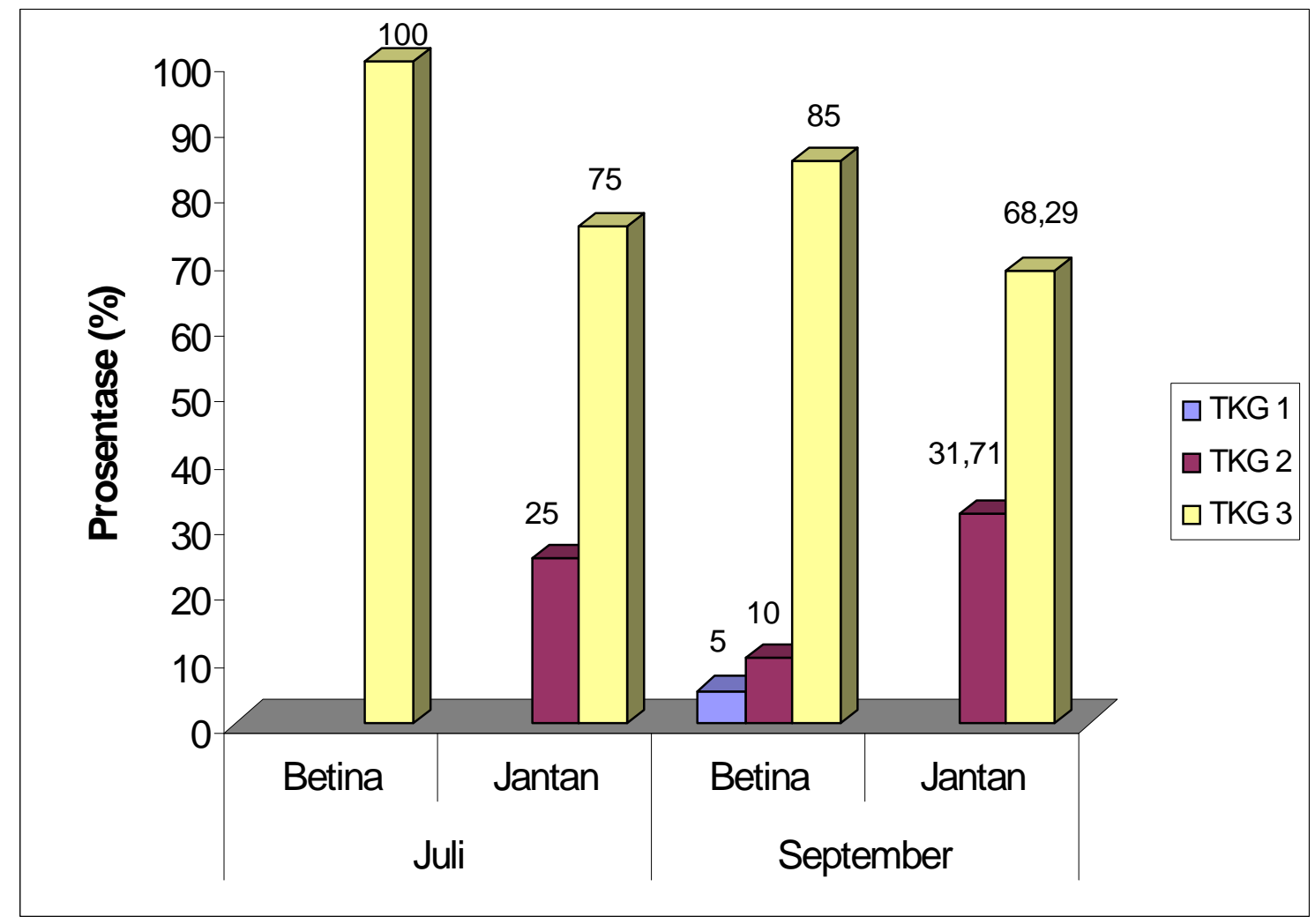

Gambar 3. Persentase tingkat kematangan gonad cakalang yang di daratkan di Bitung, pada bulan Juli dan September 2005.

\section{FEKUNDITAS}

Fekunditas adalah dasar untuk mengetahui potensi reproduksi dan ukuran stok. Dengan fekunditas ini akan diketahui jumlah ikan yang akan menetas dari induk. Dalam proses reproduksi selain dipengaruhi jumlah telur yang dibuahi juga dipengaruhi oleh pertumbuhan dan mortalitas baik secara alami maupun predasi.

Gambar 4, memperlihatkan fekunditas cakalang berkisar antara 1.000 .000 sampai dengan 14.000 .000 butir untuk ikan betina dengan panjang cagak berkisar antara 49 sampai dengan $61 \mathrm{~cm}$. Fekunditas cakalang terlihat sangat fluktuatif dan mencapai puncak pada panjang cagak 54 dan $61 \mathrm{~cm}$ sehingga tidak terlihat ada hubungan antara fekunditas dengan panjang cagak.
Menurut Suhendrata \& Merta (1986), fekunditas cakalang di perairan Sorong berkisar antara 120.000 sampai dengan 570.000 butir untuk ikan dengan panjang cagak berkisar antara 47 sampai dengan 60 $\mathrm{cm}$. Matsumoto et al. (1984) dalam Collete \& Nauen (1983) mengatakan fekunditas ikan cakalang berkisar antara 80.000 sampai dengan 2.000 .000 butir untuk ikan betina dengan panjang cagak berkisar antara 41 sampai dengan $87 \mathrm{~cm}$. Penelitian oleh Stequert \& Ramcharrun (1995) ditemukan bahwa ikan cakalang betina dengan panjang cagak $44 \mathrm{~cm}$ mempunyai fekunditas 80.000 butir, sedangkan untuk ikan yang panjang cagak $75 \mathrm{~cm}$ mempunyai fekunditas 1.250 .000 butir telur. Berdasarkan pada hasil tersebut diambil kesimpulan bahwa fekunditas bervariasi dari 40 sampai dengan 130 butir per $g$ bobot ikan. 


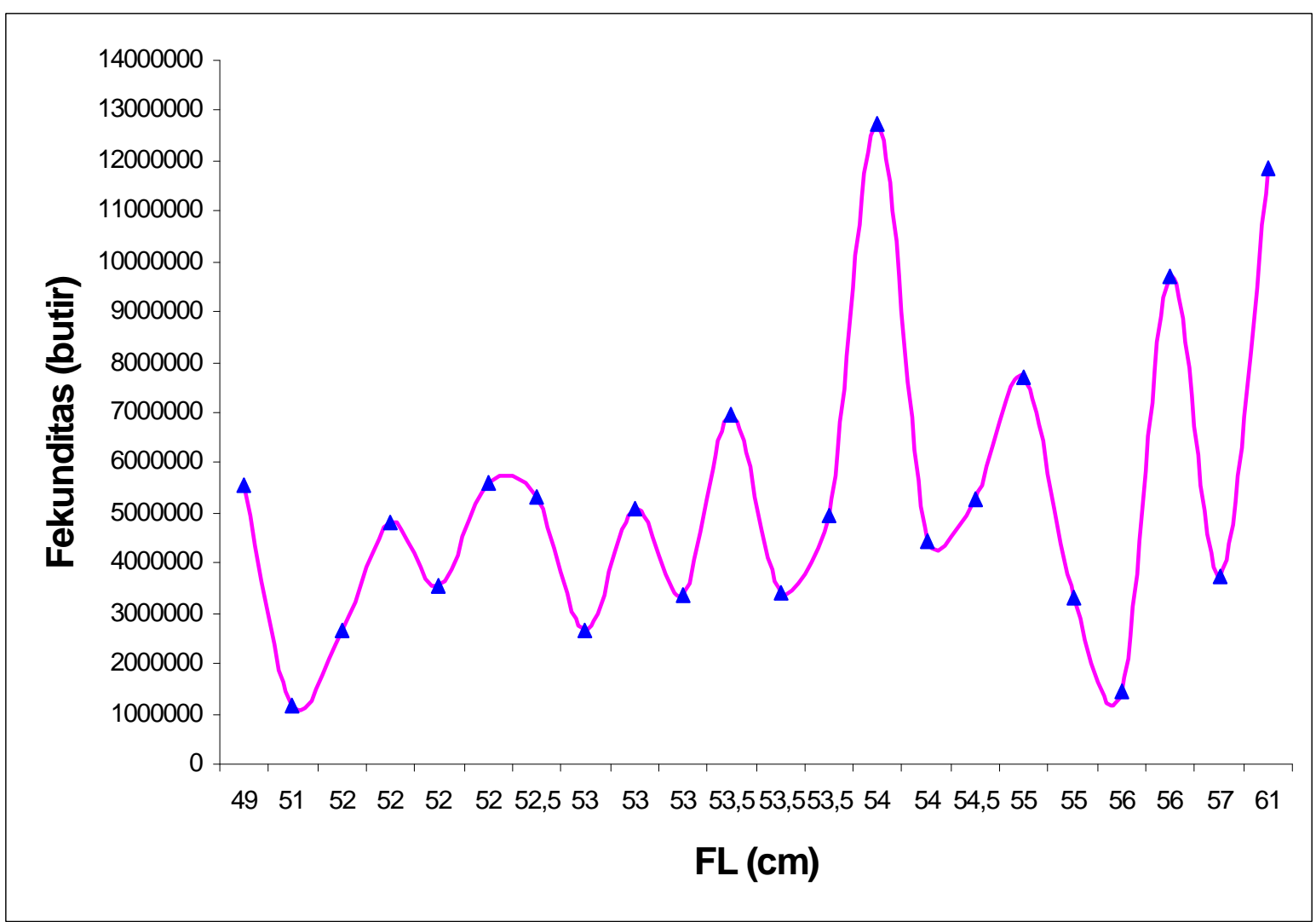

Gambar 4. Fekunditas ikan cakalang betina yang didaratkan di Bitung pada bulan Juli dan September 2005.

\section{KESIMPULAN}

Analisis biologi ikan cakalang yang didaratkan di Bitung pada bulan Juli dan September 2005 diperoleh hubungan panjang bobot ikan bersifat allometrik positif. Perbandingan jenis kelamin betina dan jantan pada bulan Juli 1:0,73, sedangkan pada bulan September 1:2,05. Tingkat kematangan gonad baik jantan maupun betina didominasi oleh stadia III. Fekunditas telur ikan cakalang betina berkisar antara 1.000 .000 sampai dengan 14.000 .000 butir.

\section{PERSANTUNAN}

Kegiatan dari hasil riset kelimpahan sumber daya ikan pelagis besar di Laut Halmahera dan Laut Sulawesi, T.A. 2005, di Balai Riset Perikanan LautMuara Baru, Jakarta.

\section{DAFTAR PUSTAKA}

Bal, D. V. \& K. V. Rao. 1984. Marine fisheries. Tata Mc. Graw-Hill Publishing Company Limited. New Delhi. p 5-24.
Batts, S. B. 1972. Sexual maturity, fecundity, and sex ratio of skipjack tuna (Katsuwonus pelamis, Linn) in North Caroline Waters. Trans. American Fisheries Society. 101. 4. 626-637.

Brock, V. E. 1954. Some Aspect of the biology of the aku, Katsuwonus pelamis in the Hawaiian Island. Pac. Sci. 8. 1. 94-104.

Collette, B. B. \& Nauen, C. E. 1983. FAO Species catalogue. Vol.2. Scombridae of the World, An Annotated and Illustrated Catalogue of Tunas, Mackerels, Bonitos, and Related Species Known to Date. United Nation Development Programme, Food, and Agriculture Organization of the United Nations. Rome. 137 pp.

Collete, B. \& C. Nauen. 2000. Katsuwonus pelamis (Linnaeus, 1958). http:// animaldiversity.ummz.umich.edu/local/ redirect.php/http://www.fao/1

Direktorat Jenderal Perikanan. 1996. Statistik Perikanan Indonesia. Departemen Pertanian. 
Evans, L. C., A. D. Uy \& D. D. Tandog. 1978. The abundance, biology, and distribution of tuna (Family Thunnidae) in Cumiguin and Nearby Waters. Philippine Dept. Nat. Resour. Bureau Fish. Aquatic Resour. Prelim. Rep. 55 p.

Gauldie, R. \& G. Sharp. June 1996. Skipjack Velocity, Dwell Time and Migration. Fisheries Oceanography. 5. 100-113.

Habib, G. 1978. Skipjack biology and the 1976 until 1977 purse seine fishery. In Proceedings of the Pelagic Fisheries Conference. July 1977. edited by G. V. Habib \& P. E. Roberts. Occas. Publ. Fish. Res. Div. New Zealand Minist. Agri. Fish. 15. 1726.

Hampton, J., Lewis A., \& Williams, P. 1999. The western and Central Pacific tuna fishery: Overview of the fishery and current of tuna stocks. Secretariate of the Pacific Community, Oceanic Fishery Programme.

Holden, M. J. \& D. F. S. Raitt (eds). 1974. Methods of resources investigations their aplication. Part 2. FIRS/T115 (Rev.1) FAO Rome. Italy. 214 p.

http://www.fishbase.org

International Committee for the Conservation of Atlantic Tunas. 1998. Report of standing committee on research on statistic. ICCAT. Madrid.

Joseph, J., W. Klawe, \& P. Murphy. 1988. Tuna and Billfish. La Jolla. CA: Inter-American Tropical Tuna Commission.

Marcille, J. \& B. Stequert. 1976. Etude Préliminaire de la Croissance du Listao (Katsuwonus pelamis) Dans l'Ouest de l'Océan Indien Tropical. Cah. ORSTOM (Ser.Oceanogr.). 14. 2. 139-51.

Matsumoto, W. M., R. A. Skillman, \& A. E. Dizon. 1984. Synopsis of biological data on skipjack tuna, Katsuwonus pelamis. NOAA Tech. Rep. NMFS Circ. 451.92 p.
Muus, B. \& J. Nielsen. 1999. Sea fish. Denmark: Scandanavian fishing year book.

Schaefer, K. M. 1988. Time and frequency of spawning of yellow fin tuna at Clipperton Island, and plans for future studies. In Proceedings of Tuna Fishery Research Conference, Far Seas Fishery Research Laboratory. Maguro Giyiroku, Suisancho-Enyo Suisan Kendyusho. 118-26.

Schaefer, M. B. \& C. J. Orange. 1956. Studies on the sexual development and spawning of yellow fin tuna (Neothunnus macropterus) and skipjack (Katsuwonus pelamis) in three areas of the eastern Pacific Ocean, by examination of gonads. Bulletin I-ATTC. 1. 6. 281-349.

Stequert, B. \& B. Ramcharrun. 1995. The fecundity of skipjack tuna (Katsuwonus pelamis) from the western Indian Ocean. Aquatic Living Resources. 8. 79-89.

Suhendrata, T. \& I G.S. Merta. 1986. Hubungan panjang bobot, tingkat kematangan gonad, dan fekunditas ikan cakalang, Katsuwonus pelamis Linnaeus, di perairan Sorong. Jurnal Penelitian Perikanan Laut. 34. 11-19.

Tester, A. L. \& E. L. Nakamura. 1957. Catch rate, size and sex of tunas and other pelagic fishes taken by trolling off Oahu, Hawaii. 1951-55. Spec. Sci. Rep. U. S. Fiah Wild. Serv. (Fish). 250. 25 p.

Wade, C. B. 1950. Observation on the spawning of Philippine tuna. Fisheries Bulletin. U. S. Fish Wild. Serv. 51. 55. 409-23.

World Wild Fund for Nature. 1996. The large pelagic fishes.

Waldron, K. D. 1963. Synopsis of biological data on skipjack Katsuwonus pelamis (Linnaeus) 1758 (Pacific Ocean). In H. Rosa, Jr. (ed.). Proceedings World Scientific Meeting on the Biology of Tunas and Related Species. Fisheries Report FA0. 2. 6. 695-748. 